\author{
Cadernos de \\ ESTUDOS LINGǘĺsTICOS - (57.2), Campinas, Jul./Dez. 2015
}

\title{
A INFLUÊNCIA DA EPISTEMOLOGIA E TEORIA SAUSSURIANAS NA TERMINOLOGIA DESCRITIVA DE BASE LINGUÍSTICA
}

\author{
MÁRCIA DOS SANTOS DORNELLES \\ Universidade Federal do Rio Grande do Sul
}

\begin{abstract}
RESUMO: Muitos são os terminólogos descritivistas que, ainda hoje, quase um século após a publicação do Curso de Linguística Geral de Ferdinand de Saussure, apoiam-se, nos seus estudos e práticas terminológicos, em princípios e conceitos básicos desenvolvidos na epistemologia e na teoria saussurianas. Isso porque, para a Terminologia descritiva de base linguística, a linguagem especializada não constitui uma linguagem artificial, à parte do sistema da língua; portanto, o termo nada mais é do que um signo linguístico que adquire estatuto terminológico num contexto especializado, segundo critérios semânticos, discursivos e pragmáticos. Assim, falar em Terminologia é falar em Linguística. Este trabalho busca, então, revisitar brevemente as noções saussurianas de signo, significação, valor, entidade, identidade e arbitrário relativo, e relacioná-las com seus desdobramentos para a Terminologia descritiva de base linguística, com ênfase no fenômeno da variação terminológica.

Palavras-chave: Teoria saussuriana; Terminologia; Variação terminológica.
\end{abstract}

RESUMEN: Muchos son los terminólogos descriptivistas que, aún hoy, casi un siglo después de la publicación del Curso de Lingüística General de Ferdinand de Saussure, se apoyan, en sus estudios y prácticas de terminología, en principios y conceptos básicos desarrollados en la epistemología y la teoría saussurianas. Eso porque, para la terminología descriptiva de base lingüística, el lenguaje especializado no constituye una lengua artificial, apartada del sistema de la lengua; por lo tanto el término no es más que un signo lingüístico que adquiere estatus terminológico en un contexto especializado, según criterios semánticos, discursivos y pragmáticos. Así, hablar de Terminología es hablar de Lingüística. Este trabajo busca, entonces, revisitar brevemente las nociones saussurianas de signo, significado, valor, entidad, identidad y arbitrario relativo, y relacionarlas con sus desdoblamientos para la terminología descriptiva de base lingüística, con énfasis en el fenómeno de la variación terminológica.

Palabras clave: Teoría saussuriana; Terminología; Variación terminológica.

\section{1. É O PONTO DE VISTA QUE CRIA O OBJETO}

Partindo do princípio epistemológico de Saussure de que "é o ponto de vista que cria o objeto" (CLG1: 15), pode-se dizer que, em Terminologia ${ }^{2}$, em virtude

\footnotetext{
${ }^{1}$ Neste artigo, a sigla CLG refere-se à $3^{\mathrm{a}}$ ed. (1971) do Curso de Linguística Geral (ver Referências). Neste formato, após os dois-pontos segue-se a página da citação.

${ }^{2}$ Terminologia (com $T$ maiúsculo) refere-se, neste artigo, à disciplina ou ao campo de estudos teórico e aplicado dedicado aos termos e a outras unidades com valor terminológico empregados nos diferentes âmbitos do conhecimento especializado. Ao conjunto desses termos e unidades maiores com valor terminológico denomina-se terminologia, com $t$ minúsculo (cf. DORNELLES, 2015).
} 
da existência de diferentes pontos de vista em relação ao papel da Terminologia e das terminologias, há também diferentes objetos de estudo, a saber: os termos, as fraseologias, as definições e o texto especializado como um todo. Tomando aqui o termo como objeto de análise, ainda assim as concepções que dele se têm são distintas - algumas complementares entre si -, a depender da vertente teórica seguida. Cada teoria, seguindo a terceira tarefa da Linguística explicitada no CLG (p. 13), vai, então, "delimitar-se e definir-se a si própria" e elaborar sua metodologia de acordo com as suas concepções e as hipóteses formuladas para criação e tratamento dos fatos da língua. Como bem observa Normand (2009b: 35): "Interrogar-se sobre o que se faz em uma descrição e em uma reflexão sobre uma língua, buscar qual é o modo de proceder adequado, é tomar uma posição epistemológica".

Assim, para desenvolver nossas reflexões neste artigo, optamos por não nos firmar numa teoria específica e sim nos apoiar genericamente na grande corrente da Terminologia descritiva de base linguística, em contraposição à teoria clássica, a chamada Teoria Geral da Terminologia (TGT). De acordo com o CLG (p. 79), "Para certas pessoas, a língua, reduzida ao seu princípio essencial, é uma nomenclatura, vale dizer, uma lista de termos que correspondem a outras tantas coisas. [...] Tal concepção é criticável em numerosos aspectos." Essa crítica de Saussure à visão reducionista da língua é essencialmente a mesma que os adeptos à Terminologia descritiva de base linguística fazem à TGT.

A TGT, fundada pelo engenheiro austríaco Eugen Wüster (1898-1977), faz uma divisão clara entre língua comum (lugar das palavras) e "línguas de especialidade" (lugar dos termos). Segundo essa teoria, "uma língua de especialidade é composta por uma rede interligada de conceitos especializados" (ZILIO, 2011: 120). Nela, a modo de etiqueta, "um termo é uma denominação que se refere, de forma unívoca dentro da área, a um conceito" (ZILIO, 2011: 120), sendo ambos considerados entidades autônomas em relação ao sistema da língua. Na ótica do prescritivismo, a TGT postula a normalização dos termos de modo a promover a desambiguação da comunicação especializada. No entanto, a concepção de normalização de Wüster é hoje entendida pelos terminólogos ${ }^{3}$ variacionistas como uma tentativa de normatização, ou seja, de imposição de uma forma por procedimentos normativos.

É o próprio Wüster quem define que "Uma unidade terminológica consiste em uma palavra à qual se atribui um conceito como seu significado (...), ao passo que, para a maioria dos linguistas atuais, a palavra é uma unidade inseparável composta de forma e conteúdo" (WÜSTER, 1998: 21, apud KRIEGER; FINATTO, 2004: 76). Relativamente a essa noção, o CLG (p. 135) adverte que "Se as palavras estivessem encarregadas de representar os conceitos dados de antemão, cada uma delas teria, de uma língua para outra, correspondentes exatos para o sentido; mas não ocorre assim". Na mesma linha, Clas (2004: 236) pondera que "Se o

\footnotetext{
${ }^{3}$ Compreendendo a dupla face da Terminologia como teoria e prática (cf. KRIEGER; FINATTO,
} 2004), neste artigo terminólogo designa aquele que se dedica a estudos e práticas terminológicos. 
Cadernos de ESTUDOS LINGüISTIICOS (57.2) - Jul./Dez. 2015

conhecimento é transmitido pela linguagem, não se deve, contudo, deduzir disso que há uma equivalência perfeita entre conhecimento e sentido linguístico".

Nesta crítica feita por Cabré Castellví (1999: 69) à teoria clássica, ficam claras, por oposição, as duas concepções gerais de termo: de um lado, uma unidade de conhecimento restrita à dimensão conceitual e à condição denominativa; de outro, uma unidade pragmático-linguística, configurando uma entidade complexa e multifacetada, com dimensões linguística, cognitiva e sociocultural.

[...] la teoría [TGT] da muestras de reduccionismo en diferentes aspectos de sus concepciones y de sus prácticas: la concepción global de la unidad terminológica, la reducción de la unidad terminológica a su condición denominativa, el olvido de los aspectos sintácticos de las unidades terminológicas, la ignorancia de los aspectos comunicativos de los términos, o la insistencia en negar la variación formal y conceptual de los términos.

Feita essa breve diferenciação entre as duas leituras gerais que hoje se fazem do papel das terminologias, passaremos a nos concentrar nisto em que as teorias terminológicas descritivas de base linguística são unânimes em reconhecer: os termos como signos da língua natural, portanto suscetíveis a toda gama de fenômenos que nesta ocorrem.

\section{O TERMO COMO SIGNO LINGUÍSTICO}

Antes de tudo, vale registrar que, para chegar a esse postulado, os terminólogos descritivistas realizaram, ao menos parcialmente, três outras tarefas fundamentais da Linguística expressas no CLG (p. 13): a descrição, a história e a generalização. Ou seja, os fenômenos envolvidos no surgimento, na consagração (imutabilidade) e na variação (mutabilidade) dos termos foram observados e descritos em várias línguas para se "deduzir essa lei geral" de que o comportamento dos termos segue a gramática (o sistema) de suas línguas naturais.

Sobre a interdependência do léxico e da gramática, que naturalmente afeta as terminologias, Normand (2009a) atesta que Saussure recusava-se a separá-los, ao contrário do que alguns críticos afirmaram. Para tanto, ampara-se no seguinte trecho do Curso: "A interpenetração da morfologia, da sintaxe de da lexicologia explica-se pela natureza, no fundo idêntica, de todos os fatos de sincronia" (CLG: 158, apud NORMAND, 2009a: 108). E ele acrescenta: "Não pode haver entre eles nenhum limite traçado de antemão" (CLG: 158).

Os procedimentos metodológicos de observação in vivo e descrição são hoje comuns a boa parte dos estudos descritivos das terminologias; já os estudos prescritivos, com sua “contínua confusão entre o que é o que queríamos que fosse

${ }^{4}$ Cabré Castellví, fundadora da Teoria Comunicativa da Terminologia (TCT), desenvolveu a noção de poliedricidade da unidade terminológica: ao mesmo tempo uma unidade linguística, uma unidade cognitiva e uma unidade sociocultural. Dessa forma, na TCT a prática terminológica também é tridimensional. 
a terminologia, que no fundo esconde a dicotomia entre língua real e língua ideal"5 (CABRÉ CASTELLVÍ, 1999: 74), parecem desconsiderar a matéria mesma da Linguística, caracterizada no CLG (p. 13) como "não só a linguagem correta e a 'bela linguagem', mas todas as formas de expressão". Também parecem ignorar o aspecto social das terminologias, como parte das línguas naturais; e o método geral da sincronia, definido no CLG (p. 106):

A sincronia conhece somente uma perspectiva, a das pessoas que falam, e todo o seu método consiste em recolher-lhe o testemunho; para saber em que medida uma coisa é uma realidade, será necessário e suficiente averiguar em que medida ela existe para a consciência de tais pessoas.

Com relação ao estudo diacrônico - que no CLG (p. 105-106) tem menor importância para a "verdadeira linguística" que o estudo sincrônico -, observase que ele também é menos privilegiado na área da Terminologia descritiva. Isso se deve, muito provavelmente, à própria função atribuída aos produtos terminográficos, grosso modo, a de repertoriar os termos usuais em uma área do saber, no intuito de auxiliar na "solução de problemas relacionados com a informação e a comunicação"6 (CABRÉ CASTELLVÍ, 1999: 71). O destaque que Normand (2009b: 56) faz da funcionalidade do sistema da língua vale também para o papel das terminologias na comunicação especializada, já que integram esse mesmo sistema:

[...] os membros de uma mesma comunidade se compreendem ou, ao menos, [...] se reconhecem como pertencentes a essa comunidade, tendo em comum as mesmas possibilidades de expressão (palavras, variação de formas, construções gramaticais...). Esse problema é, propriamente, aquele do gramático: não se trata mais da função de representação, nem da história, mas do funcionamento, que obriga a colocar a existência de um mecanismo comum [...].

Ainda em relação ao funcionamento gramatical (sistêmico) das terminologias, Krieger e Finatto (2004: 79), fazem estas observações, com grifos nossos:

[...] os termos revelam sua naturalidade aos sistemas linguísticos de várias formas, sendo uma delas a consonância aos padrões morfossintáticos das línguas que os veiculam, independentemente de serem originais ou corresponderem a estruturas neológicas. Assim, também, tal como as outras unidades lexicais dos sistemas linguísticos, as especializadas sofrem processos de sinonímia e comportam variações das mais diferentes naturezas.

No mesmo plano formal, outro exemplo de que o dinamismo da linguagem incide sobre a constituição das terminologias reside na polivalência [funcional] que caracteriza determinadas unidades lexicais, quando estas participam de mais de uma terminologia, expressando diferentes significados em cada campo do saber [...]. Trata-se do princípio de economia da língua [...]

Neste ponto, é preciso advertir que, na teoria saussuriana, não existem os conceitos semânticos de homonímia, sinonímia, polissemia, metáfora e metonímia presentes na Terminologia descritiva de base linguística. Ora, o motivo é bem

\footnotetext{
${ }^{5}$ Tradução nossa

${ }^{6}$ Tradução nossa.
} 
simples: como um signo decorre da associação entre um significante e um significado, cada vez que um desses elementos é modificado, tem-se um novo signo. No entanto, o CLG (p. 127) legitima a elaboração de classificações de palavras e a criação de conceitos em Linguística, desde que correspondam a "fatores constitutivos do sistema da língua" e partam da "distinção das partes no discurso", a exemplo do emprego da palavra "sinônimo" que faz na p. 134.

Para escapar às ilusões, devemos nos convencer, primeiramente, de que as entidades concretas da língua não se apresentam por si mesmas à nossa observação. Mas se procurarmos apreendêlas, tomaremos contato com o real; partindo daí, poder-se-ão elaborar todas as classificações de que tem necessidade a Linguística para ordenar os fatos de sua competência. (CLG: 127)

Almeida (2010), após apontar as dificuldades de identificar o termo utilizando critérios estritamente formais, já que ele não possui, necessariamente, uma estrutura prototípica, recorre a Cabré para responder á sua própria pergunta:

\footnotetext{
Que critérios devemos levar em conta para distinguir um termo de uma palavra, já que a partir de uma perspectiva linguística todos são igualmente signos da língua natural? Não existe, pois, um conjunto de termos isolados constituindo uma língua marginal à língua geral; o que há são signos da língua natural que se realizam ora como palavras, ora como termos, dependendo da temática, dos usuários, da situação comunicativa (CABRÉ CASTELLVÍ, 1999; 2003). O que distingue, portanto, termo de palavra são critérios pragmáticos. Em outras palavras: quem diz o quê? Para quem? Em que situação? (ALMEIDA, 2010: 77)
}

Para esmiuçar essa importante questão da Terminologia, assumimos uma proposta que inicia com a discussão nas noções de significação, ressignificação e valor terminológicos (na perspectiva do falante), e passa, em seguida, à discussão das noções de entidade, identidade e valor terminológicos (na perspectiva do linguista).

\section{SIGNIFICAÇÃO, RESSIGNIFICAÇÃO E VALOR TERMINOLÓGICOS}

Assumimos que é a partir da significação, tomada aqui como a atualização no discurso de um significado para um significante, que um signo adquire valor "completo". Para significar, o falante opera relações e diferenças entre termos linguísticos, as quais se desenvolvem em duas esferas distintas, cada uma "geradora de certa ordem de valores" (CLG: 142): relações associativas (in absentia, ou seja, relações entre termos no cérebro, portanto fora do discurso) e relações sintagmáticas (in praesentia, ou seja, relações no discurso entre termos que oferecem algo de comum, em virtude de seu encadeamento, baseadas no caráter linear da língua) (CLG: 142-143).

A relação sintagmática existe in praesentia; repousa em dois ou mais termos igualmente presentes numa série efetiva. Ao contrário, a relação associativa une termos in absentia numa série mnemônica virtual. (CLG: 143) 
Separadas apenas para fins didáticos e metodológicos, essas relações ocorrem de forma simultânea e interdependente, donde se concebe que, juntas, resultam na significação. Em outras palavras, entendemos que a significação de uma unidade concretiza-se no eixo sintagmático, mas nela estão envolvidas também relações in absentia. Encontramos respaldo para essa afirmação no próprio CLG (p. 151), ao afirmar que "Assim, nessa operação, que consiste em eliminar mentalmente tudo quanto não conduza à diferenciação requerida no ponto requerido, os agrupamentos associativos e os tipos sintagmáticos estão ambos em jogo" (CLG: 151); e também em Gadet (1989) e Normand (2009b):

Os dois eixos podem certamente ser contrastados termo por termo, mas o essencial é que não sejam considerados isoladamente: eles se condicionam reciprocamente, e a sequência resulta de sua interação.? (GADET, 1989: 81)

[...] a significação se produz nas relações que podem ser analisadas segundo dois eixos: o eixo das escolhas, que Saussure chama de eixo associativo, e o eixo das combinações, chamado de sintagmático. [...] A análise sincrônica exige que se leve em conta a igualdade dos eixos que formalizam separadamente o que, na fala, se produz ao mesmo tempo: as construções dos sintagmas e as operações de escolha [...]. (NORMAND, 2009b: 95)

Outra classificação que pode ser feita é que existe um valor interno ao signo e um valor na relação dele com os demais (com todos os signos da língua e com os signos presentes na cadeia da fala). Normand (2007) resume bem essa noção: “a troca figurada nessas 'delimitações recíprocas de unidades' produz valores, isto é, ligações arbitrárias entre significantes e significados, e relações, contingentes, mas reguladas em um sistema, entre as unidades". Na definição do linguista e terminólogo Loïc Depecker (2012: 143), “os valores são a resultante das diferenças e oposições em ação entre os termos do sistema".

Tanto essas relações como os valores produzidos são inconstantes, ou "voláteis", pois se atualizam a cada momento na significação; e assim o próprio "tesouro" da língua depositado na memória vai-se renovando com a comunicação entre os falantes, pois “a fala daquele que fala entra no 'tesouro íntimo' daquele que ouve (DEPECKER, 2012: 137). Portanto, o valor de um signo não é dado $a$ priori. "O valor de qualquer termo que seja está determinado por aquilo que o rodeia" (CLG: 135). Dito de outra forma, "a língua [é] um sistema em que todos os termos são solidários e o valor de um resulta tão-somente da presença simultânea de outros" (CLG: 133); ou seja, "um valor [é] determinado por suas relações com outros valores semelhantes, e sem eles a significação não existiria (CLG: 136).

Transpondo essas noções à Terminologia descritiva de base linguística, recorremos a Zilio (2011: 125), que reforça a vinculação essencial entre contexto, significação e valor terminológico:

Se entendemos que a significação de uma unidade se dá no eixo sintagmático, também entendemos que um termo somente se apresenta como tal nesse eixo. Um termo não existe,

\footnotetext{
${ }^{7}$ Tradução nossa.

${ }^{8}$ Tradução de Daniel Costa da Silva.
} 
portanto, fora de seu contexto linguístico. Em outras palavras, um termo não o é. São as palavras ou sintagmas da língua que adquirem no eixo sintagmático o valor, ou a significação, de termo. As visões que desprezam o contexto não levam em consideração essas questões linguísticas de extrema importância, como é o caso da Teoria Geral de Terminologia [...]

Clas (2004: 232) destaca o critério semântico como definidor do valor de palavra e do valor de termo:

O traço semântico da linguística é, na verdade, próprio ao caráter ou traço conceitual da terminologia. Ambos surgem de uma construção mental e são produzidos por uma conceitualização [...]. Sabe-se que as palavras podem tornar-se termos e vice-versa. A única diferença que se pode inscrever nesta oposição palavra/termo é, sem dúvida, a diferença, não de natureza, mas de conteúdo parcial, que faz com que o valor semiótico de uma palavra apóie-se em um condicionamento social, enquanto aquele do termo se baseia em um condicionamento científico que se inscreve em uma teoria ou em um modelo e tem uma certa qualidade de verificabilidade.

Nesse sentido é que se costuma dizer que um termo não é termo, mas está termo dentro de um contexto especializado, segundo critérios semânticos, discursivos e pragmáticos. Numa situação de comunicação especializada, uma unidade lexical alcança estatuto, ou valor, terminológico ao sofrer uma ressignificação, ou seja, ao adquirir um significado especializado reconhecido pela comunidade de falantes da área específica: "Um signo só é um signo porque é reconhecido como tal por uma coletividade. E o que esta lhe reconhece não é nada além do valor que ela lhe atribui" (DEPECKER, 2012: 145). Assim, só após a aceitação e a repetição de um termo pelos próprios especialistas do campo é que ele é incorporado a sua terminologia. O papel decisivo do coletivo de falantes na consagração de um termo fica claro nesta passagem do CLG (p. 132):

[...] a arbitrariedade do signo nos faz compreender melhor por que o fato social pode, por si só, criar um sistema linguístico. A coletividade é necessária para estabelecer os valores cuja única razão de ser está no uso e no consenso geral: o indivíduo, por si só, é incapaz de fixar um que seja.

Como constata Saussure, os falantes não conhecem dificuldades para delimitar um signo, já que "tudo que for significativo num grau qualquer aparecelhes como um elemento concreto, e eles o distinguem infalivelmente no discurso" (CLG: 13). E o terminólogo? Como faz para reconhecer um termo? Retornemos, então, à pergunta de Almeida (2010), sobre como distinguir um termo de uma palavra, e sigamos com a discussão das noções de entidade, identidade e valor, desta vez na perspectiva do linguista.

\section{ENTIDADE, IDENTIDADE E VALOR TERMINOLÓGICOS}

Para tratarmos dessas questões, é preciso, antes, destacar algumas passagens primorosas do CLG. O Curso enfatiza que, no discurso, "a idéia invoca, não uma forma, mas todo um sistema latente, graças ao qual se obtêm as oposições 
necessárias à constituição do signo. [...] Esse princípio se aplica aos sintagmas e às frases de todos os tipos, mesmo os mais complexos" (CLG: 151). Daí provém a sentença clássica "um signo contém toda a língua". Também observa que "quase todas as unidades da língua dependem seja do que as rodeia na cadeia falada, seja nas partes sucessivas de que elas próprias se compõem" CLG (p. 148). Na formação de uma palavra, por exemplo, "O todo vale pelas suas partes, as partes valem também em virtude de seu lugar no todo" (CLG: 148). Esta última frase, que comporta toda a teoria saussuriana, vale para toda a língua, em todos os seus níveis.

Daí provêm as dificuldades para delimitar uma entidade concreta. Assim como qualquer pessoa tem dificuldade para distinguir ou "recortar" palavras dentro da massa amorfa de sons de uma língua estrangeira que não domina, um terminólogo tampouco reconhece prontamente o que são unidades terminológicas no interior do discurso especializado de uma área com a qual não tem familiaridade. Isso porque "A língua não se apresenta como um conjunto de signos delimitados de antemão, dos quais bastasse estudar as significações e a disposição; é uma massa indistinta na qual só a atenção e o hábito nos podem fazer encontrar os elementos particulares" (CLG: 120). Assim, para o terminólogo poder analisar o funcionamento dos termos, precisa, antes de tudo, delimitá-los. "A entidade linguística não está completamente determinada enquanto não esteja delimitada, separada de tudo o que a rodeia na cadeia fônica. São essas entidades delimitadas ou unidades que se opõem no mecanismo da língua" (CLG: 120).

Pois bem, como, então, um terminólogo opõe um termo a uma palavra do léxico comum? Como ele difere, por exemplo, uma fraseologia especializada de outra colocação qualquer da língua natural? E como ele identifica as unidades terminológicas na sua formação original no discurso, considerando sua tendência à composição sintagmática?

A teoria Saussuriana responde. Lembrando que "Na língua tudo se reduz a diferenças, mas tudo se reduz também a agrupamentos" (CLG: 149), é necessário identificar as características que conferem valor terminológico a um termo e que o diferem de outras unidades lexicais da língua e de outras unidades presentes no discurso especializado de onde foram extraídas. Ao mesmo tempo, é preciso analisar a formação dessas unidades terminológicas em unidades simples e unidades complexas, incluindo as fraseologias especializadas. Gadet (1989: 76) faz um apanhado dessas noções em Saussure e cita também Rudolf Engler. Segundo ela, os termos se definem a partir de

relações de identidade e diferença entre eles num sistema de puros valores. A Linguística é, portanto, a inter-relação de signos ('Todos os fenômenos são relações entre relações', Engler, 1968 [...]. Falta descrever o mecanismo da língua, estudando a natureza das relações entre os elementos, tanto no sistema como na sua realização, através da linearidade da cadeia falada, no discurso. ${ }^{9}$

Não explicitaremos, neste artigo, as metodologias empregadas na prática terminológica descritiva de base linguística. Basta saber que o terminólogo hoje

\footnotetext{
${ }^{9}$ Tradução nossa.
} 
Cadernos de ESTUDOS LINGǘlsTicos (57.2) - Jul./Dez. 2015

conta com o valioso auxílio de tradutores, cientistas da computação e especialistas das áreas do conhecimento para a construção de produtos terminográficos cada vez mais confiáveis e sofisticados. Para além da facilidade hoje oferecida pelos softwares para reconhecimento de termos em corpora, importa frisar aqui que, na base de todo trabalho terminológico, há critérios semânticos, discursivos e pragmáticos que norteiam a identificação das unidades terminológicas. Nessa direção, Clas (2004: 236) afirma que

\begin{abstract}
A pesquisa terminológica [...] procede por hipóteses aproximativas de sentidos englobados em uma unidade linguística. É uma análise que parte, ela também, de signos linguísticos e, portanto, igualmente por semasiologia com todo o cortejo das ativações mentais. A pesquisa terminológica apóia-se em dados probabilísticos e busca a maior otimização. Então, que unidades se podem determinar? Qual é sua frequência? O que elas recobrem? Em que contextos aparecem? Como são formadas? Isso nos leva à busca de uma tipologia de conceitos. [grifos nossos]
\end{abstract}

Passemos agora a tratar de um fenômeno crucial e norteador para a corrente da Terminologia descritiva de base linguística, pois, por si só, sustenta o princípio de que as terminologias fazem parte da língua natural: a variação terminológica.

\title{
5. ARBITRÁRIO RELATIVO E VARIAÇÃO TERMINOLÓGICA
}

No capítulo dedicado a explicar o mecanismo da língua, o Curso encara um tema especialmente importante para a Terminologia: a formação das unidades linguísticas por agrupamento. Evidencia que "Via de regra, não falamos por signos isolados, mas por grupos de signos, com massas organizadas, que são elas próprias signos. Na língua tudo se reduz a diferenças, mas tudo se reduz também a agrupamentos" (CLG: 149). Esses agrupamentos resultam das solidariedades associativas e sintagmáticas, e "são elas que limitam o arbitrário" [grifo nosso] (CLG: 153).

Com essa última afirmação, a teoria saussuriana dá outra de suas reviravoltas e abre uma brecha para ventilar a radicalidade anteriormente conferida à arbitrariedade do signo; assim introduz um meio-termo: a noção de arbitrário relativo. Reconhece, então, que "não existe língua em que nada seja motivado" (CLG: 154) e, ao mesmo tempo, pondera que, "Mesmo nos casos mais favoráveis, a motivação não é nunca absoluta" (CLG: 153). Em outras palavras (CLG: 152),

O princípio fundamental da arbitrariedade do signo não impede distinguir, em cada língua, o que é radicalmente arbitrário, vale dizer, imotivado, daquilo que só o é relativamente. Apenas uma parte dos signos é absolutamente arbitrária; em outras, intervém um fenômeno que permite reconhecer graus no arbitrário sem suprimi-lo: o signo pode ser relativamente motivado [grifo nosso].

Acreditamos que reside aqui uma das principais diferenças entre a linguagem comum e a linguagem especializada. Nesta última, os termos técnico-científicos produzidos pelos falantes vinculados a uma área do saber normalmente se originam de reflexões acerca dos conceitos que buscam referir a fim de transmitir 
conhecimento. Dessa forma, buscam, motivadamente, a forma mais adequada ao significado especializado. Na ressignificação, o significado especializado muitas vezes recobre um ou mais significados comuns da unidade lexical da língua natural, sem eliminá-los. É o caso, por exemplo, de detritos celulares e trânsito intestinal, que configuram metáforas. Constata-se, pois, que, ao buscarem denominações, os especialistas estabelecem relações de forma e sentido com outras palavras e acionam um "saber gramatical" para além daquele automatizado ou intuitivo.

De acordo com Krieger e Finatto (2004: 82), o "princípio da motivação [...] preside o processo denominativo no campo do conhecimento especializado. Com isso, a arbitrariedade do signo revela-se tênue na terminologia notadamente científica." Temmerman (2000: 223, apud CLAS, 2004: 237) também destaca o princípio da motivação no âmbito da Terminologia Sociocognitiva: "as unidades de compreensão evoluem. [...] os modelos cognitivos assumem um papel no desenvolvimento de novas idéias, o que acarreta como corolário que os termos sejam motivados".

Ainda assim, a arbitrariedade do signo linguístico é citada por alguns estudiosos como uma das causas da variação dos termos. Aymerich (2003, apud ARAÚJO, 2010: 371), em sua tese de doutorado que versa sobre variação terminológica, baseiase na literatura existente para classificar as causas da existência da sinonímia nos discursos especializados. Como causas prévias, apresenta a redundância linguística, a arbitrariedade do signo linguístico e as possibilidades de variação linguística, todas inerentes às terminologias enquanto constitutivas das línguas naturais. Já as causas mais específicas são divididas em dialetais (dentre elas as geográficas, as cronológicas e as sociais); funcionais (com destaque para as diferenças no nível de especialização dos textos); discursivas (com o intuito de evitar repetição, o princípio de economia linguística, a criatividade, a ênfase e a expressividade); interlinguísticas (resultantes dos contatos linguísticos); e cognitivas (devidas a imprecisão conceitual, distanciações ideológicas e diferenças de conceitualização).

Observa-se que tanto as causas prévias como as mais específicas citadas pela autora são as mesmas para a variação de qualquer palavra do léxico comum, o que reforça o princípio de que os termos são signos linguísticos, portanto suscetíveis a toda gama de fenômenos que ocorrem na língua natural. Dentre eles, além dos já mencionados, podemos mencionar a analogia (como em escanear ou janelamento) e a aglutinação (em aquaeróbica e cicloergômetro), sejam estas mais refletidas ou mais espontâneas; a mudança fonética; e, inclusive, a etimologia popular (em western blotting). Sobre este último exemplo, uma formação da área da Química que resulta de um desdobramento do termo inglês Southern blotting, que significa o "processo mata-borrão criado por Southern" (Southern é o nome do inventor desse processo), Clas (2004: 228) explica que “a categoria linguística 'força', de certa forma, a criação de termos tirados de uma mesma série conceitual, mesmo que ela seja errônea em relação ao ponto de origem".

Ao terminógrafo que se dedica à descrição e ao tratamento dos fatos terminológicos, que são em si fatos de língua, não cabe julgar as variantes terminológicas recorrentes como mais adequadas ou menos adequadas: esse é o papel da própria comunidade de falantes da área. Uma vez aceitas por uma parte expressiva 
Cadernos de ESTUDOS LINGüISTICOS (57.2) - Jul./Dez. 2015

dessa comunidade, o que deve ser comprovado pela frequência do seu emprego nos corpora, ele deve registrá-las no repertório, ou "tesouro", terminográfico daquele campo do saber. Diferentes procedimentos metodológicos, entre si complementares, já foram propostos e aplicados para o tratamento e o registro das variantes.

Veja-se que o CLG (p. 115) situa nos falantes, e no fator tempo, o poder de modificar a língua: "tudo quanto seja diacrônico na língua não o é senão pela fala. É na fala que se acha o germe de todas as modificações: cada uma delas é lançada, a princípio, por um certo número de indivíduos, antes de entrar em uso". Vale citar, também, esta nota tomada por Riedlinger na primeira parte do curso ministrado por Saussure em 1907 e salientada por Depecker (2012: 136): “As 'inovações' [...] não saem do 'nada'. Ou seja, uma forma 'não se cria em uma assembleia de eruditos discutindo sobre o dicionário". Esta nos parece ser uma crítica tanto de Saussure como de Depecker aos linguistas e/ou terminólogos que ignoram o falante e adotam uma postura prescritivista em seu fazer.

Encerramos esta seção com esta declaração sucinta e incisiva da linguista e terminóloga variacionista Enilde Faulstich, que atua com muita força no âmbito da Socioterminologia no Brasil e no exterior: "Variação e terminologia não se confrontam na abordagem atual. Pelo contrário, defendemos que a terminologia é passível de variação porque faz parte da língua, porque é heterogênea por natureza, e porque é de uso social" (FAULSTICH, 2001: 20).

\section{A MODO DE CONCLUSÃO}

Na releitura do CLG e de diversas obras de estudiosos que refletiram sobre o pensamento de Saussure, encontramos argumentos irrefutáveis para sustentar a forte influência da epistemologia e teoria saussurianas na grande corrente da Terminologia descritiva de base linguística. As noções de signo, significação, ressignificação, valor, entidade, identidade e arbitrário permeiam esses dois espaços, e não podia ser diferente, já que a Terminologia é uma área da Linguística Aplicada.

A intenção deste trabalho foi reforçar que as terminologias fazem parte do sistema da língua, portanto os termos são signos linguísticos sujeitos a toda gama de fenômenos observados nas línguas naturais. Muitos terminólogos, filiados a diferentes teorias variacionistas, já demonstraram que a variação está presente nas terminologias, que ela deve ser estudada e repertoriada, e que ela não compromete a seriedade e a confiabilidade dos produtos terminográficos.

Ao contrário, o terminólogo que reluta contra esse ponto de vista e considera que as linguagens especializadas são "línguas de especialidade" com funcionamento autônomo em relação à língua natural tem como objeto, em consequência, o termo como entidade artificial. Portanto, ao negligenciar seus diferentes usos em situações reais de comunicação especializada e impor a normatização terminológica, elabora produtos terminográficos utilizando classificações e conceitos que podem ser considerados tendenciosos. Essa prática prescritiva configura, na nossa visão, um fazer puramente tecnicista, sem vinculação à ciência Linguística. 


\section{REFERÊNCIAS BIBLIOGRÁFICAS}

ALMEIDA, G. M. de B. Fazer Terminologia é fazer Linguística. In: PERNA, C. L.; DELGADO, H. K.; FINATTO, M. J. B. (Orgs.). Linguagens especializadas em corpora: modos de dizer e interfaces de pesquisa. Porto Alegre: EDIPUCRS, 2010. p. 72-90. Disponível em: $<$ http://www. pucrs.br/edipucrs/linguagensespecializadasemcorpora.pdf $>$. Acesso em: 04 ago. 2013.

ARAÚJJO, M. de. A constituição de uma terminologia: a contribuição de obras estrangeiras e traduzidas à criação de séries sinonímicas no português. In: ISQUERDO, A. N.; BARROS, L. A. (Orgs.). As ciências do léxico: lexicologia, lexicografia, terminologia, vol. V. Campo Grande: Ed. UFMS, 2010. p. 369-379.

CABRÉ CASTELLVÍ, M. T. Elementos para una teoría de la terminología: hacia un paradigma alternativo. In:

La terminología: representación y comunicación; elementos para una teoría de base comunicativa y otros artículos. Barcelona: IULA/Universitat Pompeu Fabra, 1999. p. 69-92.

CLAS, A. A pesquisa terminológica e a formulação de parâmetros em função das necessidades dos usuários. In: ISQUERDO, A. N.; BARROS, L. A. (Orgs.). As ciências do léxico: lexicologia, lexicografia, terminologia, vol. II. Campo Grande, MS: Ed. UFMS, 2004. p. 223-238.

DEPECKER, L. Compreender Saussure a partir dos manuscritos. Trad. Maria Ferreira. Petrópolis: Vozes, 2012.

DORNELLES, M dos S. Bases teórico-metodológicas para elaboração de um glossário bilíngue (português-inglês) de treinamento de força: subsídios para o tradutor. 2015. 364 p. Dissertação (Mestrado em Letras) - Instituto de Letras, UFRGS, Porto Alegre, RS. Disponível em: $<\underline{\text { http:// }}$ hdl.handle.net/10183/117567>.

FAULSTICH, E. Aspectos de terminologia geral e terminologia variacionista. TradTerm, v. 7, p. 11-40, 2001. Disponível em: $<$ http://www.revistas.usp.br/tradterm/article/view/49140>. Acesso em: 04 ago. 2013.

GADET, F. Saussure and contemporary culture. Trad. George Elliott. London: Hutchinson Radius, 1989.

KRIEGER, M. da G.; FINATTO, M. J. B. Introdução à terminologia: teoria e prática. São Paulo: Contexto, 2004.

NORMAND, C. Convite à Linguística. Org. Valdir do Nascimento Flores e Leci Borges Barbisan. São Paulo: Contexto, 2009a.

NORMAND, C. Saussure: une épistémologie de la linguistique. Atas de Colóquio, Séoul, 2007.

NORMAND, C. Saussure. Trad. Ana de Alencar e Marcelo Diniz. (Figuras do Saber; 23) São Paulo: Estação Liberdade, 2009b.

SAUSSURE, F. de. Curso de linguística geral. 3. ed. Org. Charles Bally e Albert Sechehaye; col. Albert Riedlinger. Trad. Antônio Chelini, José Paulo Paes e Izidoro Blikstein. São Paulo: Cultrix, 1971.

ZILIO, Leonardo. Termo e valor linguístico: uma abordagem ensaística. Cadernos do IL, Porto Alegre, n. 42, p. 119-128, 2011. Disponível em: <http://seer.ufrgs.br/cadernosdoil/article/view/26016>. Acesso em: 04 ago. 2013. 